\title{
Author Correction: Marrying chemistry with biology by combining on-chip solution-based combinatorial synthesis and cellular screening
}

\author{
Maximilian Benz (D), Mijanur R. Molla, Alexander Böser, Alisa Rosenfeld \& Pavel A. Levkin (B)
}

Correction to: Nature Communications https://doi.org/10.1038/s41467-019-10685-0, published online 28 June 2019.

The original version of this Article omitted 'The Ministry of Science, Research and the Arts Baden-Württemberg (MWK), Grant FKZ 7533-7-11-10-07 (IWWB-28)' from the acknowledgements and has since been adjusted to read:

The research was supported by the ERC Starting Grant (DropCellArray, 337077), ERC Proof-of-Concept Grant (CellScreenChip, 680913) and the Ministry of Science, Research and the Arts Baden-Württemberg (MWK), Grant FKZ 7533-7-11-10-07 (IWWB-28). We would like to thank Dr. Gerald Brenner-Weiß from IFG (KIT, Institute of Functional Interfaces) for providing training and access to MALDI-TOF mass spectrometry, and Dr. Nicole Jung from IOC (KIT; Institute of Organic Chemistry) for providing training and access to LC-MS.

This has now been corrected in both the PDF and HTML versions of the Article.

Published online: 04 December 2019

\footnotetext{
(c) Open Access This article is licensed under a Creative Commons Attribution 4.0 International License, which permits use, sharing, adaptation, distribution and reproduction in any medium or format, as long as you give appropriate credit to the original author(s) and the source, provide a link to the Creative Commons license, and indicate if changes were made. The images or other third party material in this article are included in the article's Creative Commons license, unless indicated otherwise in a credit line to the material. If material is not included in the article's Creative Commons license and your intended use is not permitted by statutory regulation or exceeds the permitted use, you will need to obtain permission directly from the copyright holder. To view a copy of this license, visit http://creativecommons.org/licenses/by/4.0/.
}

(C) The Author(s) 2019 